nature

Volume 251

September 6, 1974

\section{Should we publicise those experiments?}

THE vigorous debate, started several weeks ago by the appeal from a panel of the National Academy of Sciences for self-restraint in pursuing research on certain types of plasmid engineering, does not as yet show any sign of waning. True, the number of scientists technically qualified to appreciate the risks involved and weigh them against other considerations is relatively small, but each of them is going to wish to make a very personal contribution to the discussion since it probably concerns his way of going about research in the future. Further, there are many more scientists who may understand little or nothing of the technical content of the appeal but who can envisage quite well the sort of feelings that are aroused when a distinguished group of scientists proposes a halt to certain research work.

One of the ramifications of the proposed ban is that scientific journals might wish to take note of it in their publication policy. Thus David Baltimore, one of the NAS committee members, said "editorial boards ... will probably think twice about publishing research papers derived from experiments covered by the embargo", and Michael Stoker, Director of the Imperial Cancer Research Fund, wrote "editors ... . will also need to consider their policies in the face of wide support for a moratorium".

We are obviously capable of speaking only for Nature but it is our opinion that any policy that tries to eliminate from the journal reports of experiments that are believed--even widely believed-to be potentially dangerous would be quite wrong. We are unsure that editors of more specialised journals would necessarily feel similarly.

There are two reasons why we feel that Nature should not take a stand against such papers. The first is that asking a referee to remark on the morality of a paper (assuming that it is not a question of legality) cannot but lead to impossible situations. Should reports of nuclear fission have been called 'potentially dangerous' and in bad taste? Should scientific work emerging from nuclear detonations or weather modification be kept out of the literature? Is the administering of electric shocks to animals cruel? These are not questions which can safely be left to a referee with his own personal predilections, or even an editor with his, and to attempt to do so by putting an $\mathrm{X}$ in the box if you believe the experiment should never have been done in the first place is rather like asking a judge to deliver his verdict only after he has factored in to his decisions his own feelings about whether the law was a good one to start with. The community can either legislate against certain experiments or it can attempt to persuade practitioners to desist; if it tries to put the onus on an individual to decide for the community. it can hardly be surprised if the result is often quirky.

The second reason why we would not automatically decline papers describing things of which many would disapprove is that it is surely more important that these things be given publicity than that they be pushed into the underground.

This hardly means that we would actively solicit such manuscripts nor that we would be more likely to accept them in order to take advantage of their obviously unusual character. But if a scientist has chosen to ignore a widespread call then a case could occasionally be made for drawing the community's attention to who he is and what he is doing. Besides, proscribed experiments will need continued re-evaluation in the light of new techniques and new understandings, and it may be that research done in forbidden territory, however lacking in approval by a majority of scientists, positively helps in reinforcing or easing the moratorium.

We have a broad general sympathy with the aims of the NAS group and we recognise in their statement important ground-breaking in the scientific community. Nevertheless, we would not at present wish to commit ourselves to any blanket policy of turning away reports from those who work on regardless. The issue of publication, though, certainly merits. an airing at next February's international meeting.

\section{A hundred years ago}

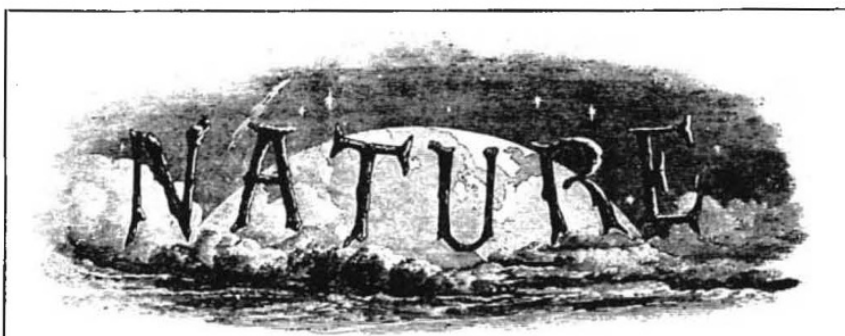

While progress has been made with gigantic strides in many directions, in engineering and in mechanics generally; while railways, steamboats, and electric telegraphs bave extencied their wonders to the most distant parts of the world; and while trade, with these aids, is bringing to our shores the produce even of the most distant places, to add to our comiorts and our luxuries ; yet, when we come to look to cur homes, to the places where most of our population have to spend ncarly the whole of their lives, I think we must find, with regret, that, in matters pertaining to the salubrity and general amcnities of our towns and houses, as places for residence, due progress in improvement has not been made. Our house drainage arrangements are habitually disgracefully bad; and this I proclaim emphatically, alike in reference to the houses of the rich and the poor. We have got, since the early part of the present century, the benefit of the light of gas in our apartments; but we allow the pernicious pro. ducts of combustion to gather in large quantities in the air we have to breathe ; and in winter evenings we live with our hends in heated and vitiated air, while our feet are ventslated with a current of fresh, cold air, gliding along the floor towards the fireplace to be draun uselessly up the chimney. A very few people have commenced to provide chimneys or flues to carry away the fumes of their more important gaslights, in like manner as we have chimneys for our ordinary fires. In mentioning this, however, as a suggestion of the course in which improvement ought to advance, 1 leel bound to cffer a few words of caution against the introduction of flue pipes for the gas flames rashly, in such ways as to bring danger of their setting fire to the house.

From the Presidential Address of Prof James Thompson to the Mechanical Science Section of the British Association, in Nature, 10, 393, Sept 10, 1874. 